\title{
Tilapia Protein Hydrolysate Enhances Transepithelial Calcium Transport in Caco-2 cells
}

\author{
Nootjaree Buaduang1, Worrapanit Chansuwan ${ }^{2}$, Nongporn Hutadilok-Towatana ${ }^{3,4,5}$, Zhe \\ Yang $^{6}$, Nualpun Sirinupong ${ }^{2}$
}

${ }^{1}$ Functional Food and Nutrition, Faculty of Agro-Industry, Prince of Songkla University, Hatyai, Songkhla 90112, Thailand; ${ }^{2}$ Interdisciplinary Graduate School of Nutraceutical and Functional Food, Prince of Songkla University, Hatyai, Songkhla 90112, Thailand; ${ }^{3}$ Biochemistry, Faculty of Science, Prince of Songkla University, Hat Yai, Songkhla 90112, Thailand; ${ }^{4}$ College of Oriental Medicine, Rangsit University, Prathum-Thani 12000, Thailand; ${ }^{5}$ Krisana Kraisintu Foundation, 13/ 217 Plum Condominiums, Phaholyothin 89, Phaholyothin Road, Prathum-Thani 12030, Thailand; ${ }^{6}$ Department of Biochemistry, Microbiology, and Immunology, School of Medicine, Wayne State University, Detroit, Michigan 48201, USA.

Corresponding author Nualpun Sirinupong, Ph.D. Interdisciplinary Graduate School of Nutraceutical and Functional Food, Prince of Songkla University, Hatyai, Songkhla 90112, Thailand

Submission Date: August $26^{\text {th }}$, 2019. Acceptance Date: October $28^{\text {th }}$, 2019. Publication Date: October $30^{\text {th }}, 2019$

Citation: Buaduang N, Chansuwan W, Hutadilok-Towatana N, Yang Z, Sirinuping N: Tilapia protein hydrolysate enhances transepithelial calcium transport in Caco2 cells. Functional Foods in Health and Disease 2019, 9(10): 678-694. DOI: https://doi.org/10.31989/ffhd.v9i10.651

\begin{abstract}
Background: Adequate calcium intake is essential for calcium balance and normal health. Prolonged deficiency of calcium is associated with osteoporosis, dental changes, cataracts, and alterations in the brain. However, calcium is difficult to be directly absorbed from food due to the insoluble calcium salt precipitation that occurs in the intestinal environment. The aim is to investigate TPH produced by Nile tilapia and the stimulation of TPH-calcium-binding activity.
\end{abstract}

Methods: Tilapia protein hydrolysate (TPH) was prepared by alcalase digestion. Calcium-binding activity was measured using calcium colorimetric assay; absorption was at $612 \mathrm{~nm}$. The interaction between TPH and calcium was examined by spectroscopic analysis, ultraviolet absorption, and fluorescence measurement. TPH-calcium-binding stability in the human digestion system was evaluated by in vitro pepsin-pancreatin hydrolysis simulating human gastric and intestinal digestion. The effects of food components on TPH-calcium-binding activity was also analyzed. The enhancement of transepithelial calcium transport by TPH was determined by in vitro Caco2 epithelial cell-like monolayer. 
Results: TPH produced from Nile tilapia (Oreochromis niloticus) exhibited calcium-binding activity. Peptides in the hydrolysate that contributed to calcium binding since the spectroscopic changes induced by calcium were characteristic of peptide bonds and tryptophan residues. The calcium binding of TPH was compatible with food matrices. Most food components including saccharides, amino acids, and vitamins showed either positive or no effects on calcium binding. The calcium binding of TPH was also stable in the simulated gastrointestinal digestion system. Pepsin and pancreatin did not considerably change the calcium-binding activity of TPH. Of note, TPH reduced precipitation of calcium by oxalate and phytate, the two most anti-nutritional factors present in green leafy vegetables. Finally, we showed that TPH significantly promoted transepithelial calcium transport in the Caco- 2 cell permeability model.

Conclusions: Tilapia protein hydrolysate produced by alcalase digestion possessed calciumbinding activity and prevents precipitation of calcium by a mineral-chelating agent as well as enhanced transepithelial calcium transport in the Caco-2 cell. The result implicated the potential of TPH as a functional food ingredient for promoting calcium absorption.

Keywords: Tilapia protein hydrolysate; Calcium binding peptides; Calcium absorption

\section{INTRODUCTION}

Calcium is an essential micronutrient required for many important functions in the human body. Calcium is needed to maintain strong bones, for the muscles to move, and for nerves to send messages. Almost every activity requires calcium for proper functions [1]. Calcium is absorbed into the small intestine of mammals by two mechanisms: active and passive transports. Transcellular active transport happens largely in the duodenum and upper jejunum, whereas passive calcium transport functions throughout the intestine [2]. When the calcium content of the chyme is low, a large portion of calcium is absorbed by the transcellular active transport process. However, when the mucosal calcium concentration exceeds $5 \mathrm{mM}$, transcellular active transport is downregulated and then accounts for only a small portion of calcium uptake [3]. The passive calcium transport process does not use energy. The rate of this process can be regulated by epithelial cells via controlling the tight junction permeability to calcium [3]. However, calcium is difficult to be directly absorbed from the food due to the insoluble calcium salt precipitation that occurs in the intestinal environment [4]. Consequently, there have been strong interests in developing methods to enhance calcium uptake.

Several studies have shown that bioactive peptides can enhance calcium uptake $[5,6]$. Bioactive peptides are defined as specific protein fragments that have a positive impact on body functions and may ultimately influence health. Bioactive peptides are inactive within the sequence of their parent proteins but can be released by enzymatic hydrolysis during either gastrointestinal digestion or food processing. They usually contain 2-20 amino acid residues [7]. The studies showed that protein hydrolysate from several food sources contain calcium-binding peptides. These peptides are bioactive able to promote calcium uptake via epithelium absorption, such as casein phosphopeptides (CPPs) [8, 5, 9], chicken eggshell matrix proteins [10], and tilapia scale protein hydrolysate [6].

A recent study showed that the peptides derived from the hydrolysate of tilapia muscle could solubilize amorphous calcium phosphate [11]. The amount of calcium these peptides can solubilize 
is similar to that of CPPs do. This suggests their potential applications for improving calcium uptake. However, it remains unknown whether these peptides can enhance the transepithelial absorption of calcium. There is also a lack of systematic understanding of how common food components may affect the calcium-binding abilities of these tilapia-derived peptides.

Tilapia farming is proving to play an important role in food security in many countries. Tilapia is nutritious and forms a healthy portion of a balanced diet: high in protein (16-25\%) and low in fat $(0.5-3.0 \%)$ [12]. Tilapia is also low in carbohydrates and sodium, and its fatty acid composition is mostly unsaturated [13]. Thus, recently there have been an increase in research interest in exploring tilapia as functional foods and nutraceuticals [14]. In this study, we isolated the tilapia protein hydrolysate (TPH) that exhibited calcium-binding activity. We performed a systematic analysis of the effects of common food components on its calcium binding. Using Caco-2 cells as intestinal permeability model, we showed that TPH can significantly stimulate transepithelial calcium absorption.

\section{MATERIALS AND METHODS}

\section{Materials}

Fresh tilapia (Oreochromis niloticus), 700-900 g/fish, was purchased from a local market in Songkhla, Thailand. Alcalase 2.4 L (EC number 3.4.21.62) was purchased from Novozyme (Bagsvaerd, Denmark). QuantiChrom Calcium Assay Kit DICA-500 was purchased from Bioassay System, USA. Food components used were of food grade. Heterogeneous human epithelial colorectal adenocarcinoma cells (Caco-2 cell line) were obtained from the American Type Cell Collection (ATCC, HTB-37). Minimum Essential Medium (MEM) Gibco were purchased from ATCC. Transwell permeable supports (12 $\mathrm{mm} 2$ inserts, $0.4 \mu \mathrm{m}$ pore size, polycarbonate membrane) were purchased from Corning Costar, UK. A MilliCell ERS-2 Volt ohmmeter used to measure Transepithelial Electrical Resistance (TEER) was made by Millipore, USA. Pancreatin and pepsin were purchased from Sigma-Aldrich (St Louis, MO, USA). All other reagents and chemicals used were of analytical grade.

\section{Enzymatic hydrolysis of tilapia}

$300 \mathrm{~g}$ of fresh tilapia was cut into small pieces and minced by a meat grinder and homogenizer. The minced tilapia was mixed with deionized water in a ratio of 1:2 (w/v). The mixture was adjusted to $\mathrm{pH} 8.5$ using $6 \mathrm{~N} \mathrm{NaOH}$ and agitated for $15 \mathrm{~min}$ at room temperature. The mixture was then placed in a water bath to maintain at $55{ }^{\circ} \mathrm{C}$ before adding $1 \%$ alcalase (w/w). The mixture was hydrolyzed and agitated by an overhead stirrer from 0 to $360 \mathrm{~min}$. The hydrolysis was stopped by heating the system at $95{ }^{\circ} \mathrm{C}$ for $15 \mathrm{~min}$. Finally, the hydrolysate was centrifuged at $3000 \mathrm{x} \mathrm{g}$ for 20 min. The supernatant, referred to as TPH, was measured for protein content by the Lowry method, lyophilized, and then kept at $-20{ }^{\circ} \mathrm{C}$ for further experiments. The $60 \pm 2.5 \mathrm{~g}$ of lyophilized TPH powder contains $830 \pm 10.6 \mathrm{mg}$ protein $/ \mathrm{g}$ powder.

\section{Analysis of TPH-calcium binding activity}

The calcium-binding activity of TPH was determined by the calcium colorimetric assay kit DICA500. The lyophilized TPH was dissolved in deionized water and diluted with a buffer of $100 \mathrm{mM}$ Tris- $\mathrm{HCl} \mathrm{pH}$ 7.8. The dissolved TPH was mixed with $\mathrm{CaCl}_{2}$ in the same buffer. The mixture was gently agitated at $37^{\circ} \mathrm{C}$ for 1 hour and then centrifuged at $6,000 \times \mathrm{g}$ for $15 \mathrm{~min}$. The calcium 
content in the supernatant was determined using the calcium colorimetric assay kit. The absorbance at $612 \mathrm{~nm}$ was measured after adding the developing reagent into the reaction. The calciumbinding activity was calculated as follows: Calcium-binding activity $(\mathrm{mg} / \mathrm{ml})=$ Catotal - Cafree, where Catotal was calcium concentration measured without TPH; Cafree, calcium concentration measured after adding TPH subtracted by the calcium amount in TPH. To determine the effects of food components on TPH-calcium-binding, various concentrations of food components were added into the TPH-calcium mixtures and then the amounts of free calcium were measured.

\section{Spectroscopic analysis of TPH-calcium interaction}

The ultraviolet absorption spectra of TPH were recorded between the wavelengths $190 \mathrm{~nm}$ and $400 \mathrm{~nm}$ using a UV-visible spectrophotometer (Shimadzu, model UV-1601 PC). TPH was mixed with various concentrations of $\mathrm{CaCl} 2$ in the buffer of $100 \mathrm{mM}$ Tris- $\mathrm{HCl} \mathrm{pH} \mathrm{7.8.} \mathrm{The} \mathrm{mixtures} \mathrm{were}$ incubated for 1 hour before the spectra were recorded. Fluorescence of TPH in the absence and presence of $\mathrm{CaCl} 2$ was measured using a spectrofluorometer (Jasco FP-8200). The excitation wavelength was $280 \mathrm{~nm}$ and emission was recorded between 300-450 nm.

\section{Simulated gastrointestinal digestion system}

An in vitro pepsin-pancreatin hydrolysis simulating human gastric and intestinal digestion was carried out according to previous studies $[15,16]$. Lyophilized TPH containing $10 \mathrm{~g}$ proteins was mixed with $400 \mathrm{~mL}$ of distilled-deionized water. After the $\mathrm{pH}$ was adjusted to 2.0 with $1 \mathrm{M} \mathrm{KCl-}$ $\mathrm{HCl}$, pepsin was added at the ratio of $145 \mathrm{U} / \mathrm{g}$ proteins. The mixture was incubated at $37{ }^{\circ} \mathrm{C}$ for 3 hours. Then, the sample was submerged in a boiling water bath for $10 \mathrm{~min}$ to deactivate pepsin. After pepsin hydrolysis, TPH was adjusted to $\mathrm{pH} 7.0$ by $2 \mathrm{~N} \mathrm{NaOH}$. Pancreatin was then added into the hydrolysate at the ratio of $30 \mathrm{U} / \mathrm{g}$ proteins. The mixture was further incubated at $37{ }^{\circ} \mathrm{C}$ for 4 hours. Finally, the sample was submerged in a boiling water bath for $10 \mathrm{~min}$ to inactivate pancreatin. The digested TPH at various times were cooled down to room temperature and centrifuged at $6,000 \mathrm{x} \mathrm{g}$ for $15 \mathrm{~min}$. The calcium content in the supernatant was measured using the calcium colorimetric assay kit. The peptide patterns of the hydrolysate were determined by Tricine-Sodium Dodecyl Sulfate-Polyacrylamide Gel Electrophoresis (Tricine-SDS-PAGE).

\section{Cell culture}

The Caco-2 human colon cancer cell line was obtained from the American Type Cell Collection. Cells were cultured in $75 \mathrm{~cm} 2$ plastic flasks in the Minimal Essential Media (MEM) Gibco supplemented with $15 \%$ fetal bovine serum (FBS), $1 \%$ nonessential amino acids, $1.5 \%$ penicillin, and $1.5 \%$ streptomycin. Cells were maintained in a humidified incubator with $5 \% \mathrm{CO} 2$ at $37{ }^{\circ} \mathrm{C}$ and sub-cultured every 2 days or when the cells reached the confluence of $80-90 \%$. Cells were detached from the flasks using $0.25 \%$ trypsin-EDTA (Gibco BRL).

\section{Cell viability assay}

Cell viability was measured by MTT assay $[17,18]$. Briefly, Caco- 2 cells were seeded at a density of 1 x 105 cells per well in 96-well cell culture plates. The cells were incubated at $37{ }^{\circ} \mathrm{C}$ in $5 \%$ $\mathrm{CO}_{2}$ for 24 hours to allow them to become fully differentiated. Then, various concentrations of TPH were added into the cells, and the cells were incubated at $37{ }^{\circ} \mathrm{C}$ in $5 \% \mathrm{CO}_{2}$ for another 24 hours. Subsequently, MTT, 3-(4, 5-dimethylthiazol-2-yl)-2, 5-diphenyl tetrazolium was added into 
the cell cultures, and the cells were incubated at $37^{\circ} \mathrm{C}$ for 3 hours in the darkroom until formazan crystals formed. After the medium was removed, DMSO was added into each well to dissolve the formazan crystals. After the cells were gently agitated for $10 \mathrm{~min}$ at $37{ }^{\circ} \mathrm{C}$, absorbance was read at $570 \mathrm{~nm}$ using a microplate reader (BioTek, PowerXS, USA). Cell viability (\%) was calculated as follows: Cell viability $(\%)=[$ Mean OD sample/OD control] $x 100$, where the control sample was performed without TPH.

\section{Caco-2 cell monolayer}

To generate a Caco- 2 cell monolayer, the cells were seeded at a density of $2.6 \times 10^{4}$ cells per $\mathrm{cm}^{2}$ into transwells. The culture media were added into both apical and basolateral chambers of the transwells. The cells were incubated at $37{ }^{\circ} \mathrm{C}$ in $5 \% \mathrm{CO}_{2}$. The media were changed every 3 days for about 21 days or until the cells were fully differentiated as a monolayer as measured by transepithelial electric resistance (see below).

\section{Transepithelial Electric Resistance Measurement}

Monolayer integrity was measured by transepithelial electrical resistance (TEER) using the MilliCell ERS-2 Voltohmmeter. TEER values of 3 different positions per well were recorded every 3 days for about 21 days. When TEER values reached 400-500 $\Omega . \mathrm{cm}^{2}$, the cells were assumed to be fully differentiated as a monolayer and appropriate for nutrient or calcium transport studies. TEER measurement involves measuring the blank resistance $\left(\mathrm{R}_{\text {blank }}\right)$ of the semipermeable membrane only (without cells) and measuring the resistance across the cell layer on the semipermeable membrane $\left(\mathrm{R}_{\text {total }}\right)$ in units of $\Omega$ [19]. The cell-specific resistance $\left(\mathrm{R}_{\text {tissue }}\right)$ is obtained as $R_{\text {tissue }}(\Omega)=\left(R_{\text {total }}-R_{\text {blank }}\right)$. The resistance is inversely proportional to the effective area $\left(\mathrm{cm}^{2}\right)$ of the semipermeable membrane $\left(\mathrm{M}_{\text {area }}\right)$. TEER values are typically reported in units of $\Omega . \mathrm{cm}^{2}$ and calculated as: TEER $=\mathrm{R}_{\text {tissue }}(\Omega) \times \mathrm{M}_{\text {area }}\left(\mathrm{cm}^{2}\right)$. The area of the insert membrane $\left(\mathrm{M}_{\text {area }}\right)$ in this study is $1.12 \mathrm{~cm}^{2} /$ well.

\section{Calcium transport across Caco-2 cell monolayer}

Calcium transport experiments were performed using Caco-2 cell monolayers in transwells with a transport buffer containing (mM) $140 \mathrm{NaCl}, 5.8 \mathrm{KCl}, 0.34 \mathrm{Na}_{2} \mathrm{PO}_{4}, 0.44 \mathrm{KH}_{2} \mathrm{PO}_{4}, 0.8 \mathrm{MgSO}_{4}, 20$ $\mathrm{N}$-Z-hydroxyethyl piperazine-N'-2-ethane sulfonic acid, 4 glutamine, and 25 D-glucose (pH 7.4). The transwell inserts were placed in 12-well culture plates. Various concentrations of calcium and/or TPH in the transport buffer were applied into the apical chambers of the transwells. The transport buffer only was added to the basolateral chambers. The transwell plates were gently agitated in a shaking incubator at $37^{\circ} \mathrm{C}$ for $150 \mathrm{~min}$. An aliquot of the samples in the basolateral chambers was collected every $30 \mathrm{~min}$ from 0 to $150 \mathrm{~min}$ for the determination of calcium content. The calcium concentration was determined using the calcium assay kit as described previously. The efficiency of calcium transport was expressed as the permeability coefficient (Papp) [20] which was calculated according to the equation: Permeability coefficient $($ Papp $)(\mathrm{cm} / \mathrm{s})=$ $(d \mathrm{Q} / d \mathrm{t}) /\left(\mathrm{C}_{0} \times \mathrm{A}\right)$, where $d \mathrm{Q} / d \mathrm{t}$ is the amount of calcium in basolateral chamber as a function of time $(\mu \mathrm{mol} / \mathrm{s}) ; \mathrm{C}_{0}$, the initial concentration of calcium in apical chamber $(\mathrm{mol} / \mathrm{L}) ; \mathrm{A}$, the area of filter insert $\left(1.12 \mathrm{~cm}^{2}\right)$.

\section{Statistical analysis}

All experiments were done in triplicate. Data were expressed as mean $\pm \mathrm{SD}$. The differences among the groups were analyzed by one-way ANOVA followed by Duncan's multiple-comparison 
test using SPSS software (version 22.0, IBM). The p-value of less than 0.05 was considered to be significant. In Figures, mean values with different letters were significantly different and values with the same letters not significantly different.

\section{RESULTS AND DISCUSSION}

\section{Production of calcium-binding tilapia protein hydrolysate (TPH)}

Tilapia protein hydrolysate (TPH) was generated by incubating minced tilapia with Alcalase. The hydrolysate was measured for calcium binding at different time intervals during the hydrolysis (Figure 1). The calcium-binding activity increased by more than two-fold for the first 30 min of hydrolysis. The highest calcium binding activity was found at $240 \mathrm{~min}$. There was no significant activity change between 270 and $360 \mathrm{~min}$. This result is consistent with our previous study that the calcium-binding activity of TPH was dependent on the time of hydrolysis [11]. The hydrolysate at $240 \mathrm{~min}$ of hydrolysis was selected for further experiments.

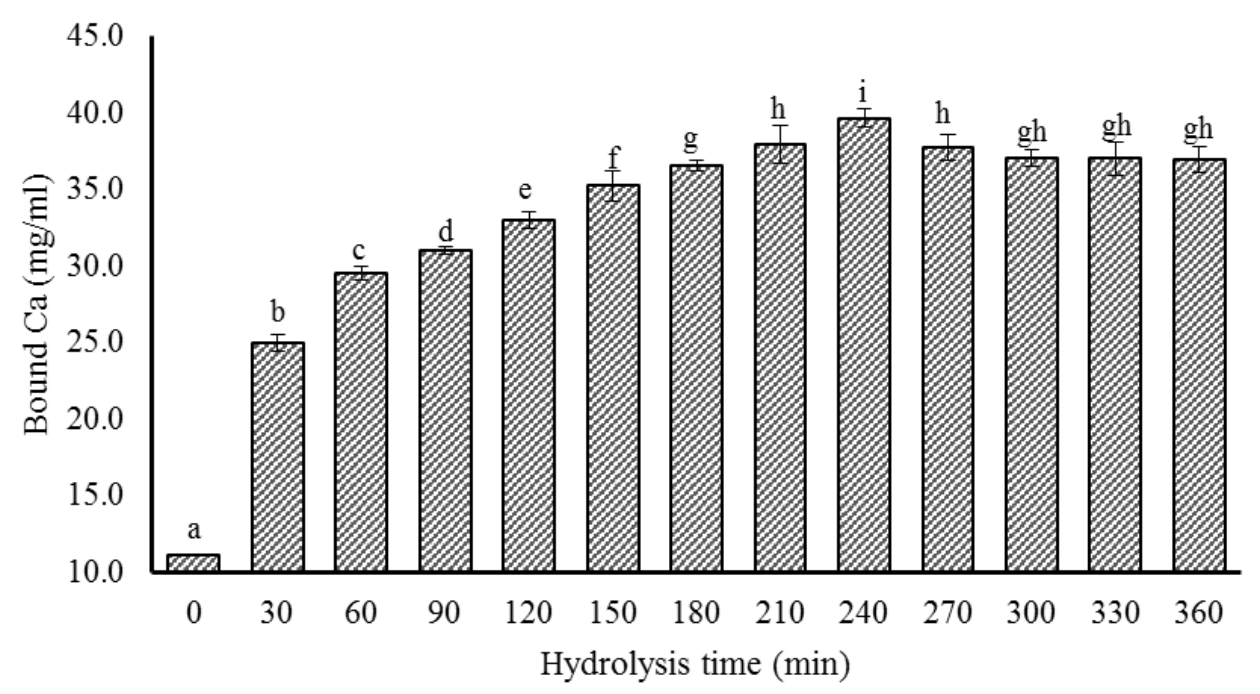

Figure 1. TPH calcium-binding activities at different hydrolysis times. Mean values with different letters were significantly different $(\mathrm{p}<0.05)$.

\section{Spectroscopic characterization of TPH-calcium interaction}

To confirm the interaction between TPH and calcium, spectroscopic analysis of TPH in the presence of various concentrations of $\mathrm{CaCl}_{2}$ was evaluated (Figure 2). In ultraviolet spectroscopy, the strongest absorption peaks were observed in the range of 210-236 nm (Figure 2A). This absorption is characteristic of peptide bonds and their carbonyl groups. At no or low calcium concentrations $(0-2.5 \mathrm{mM})$, the strongest absorption peaks were found at $229 \mathrm{~nm}$, whereas the peaks shifted to $226 \mathrm{~nm}$ when calcium concentration increased (Figure 2B). Increased calcium concentration also increased the absorbance of the maximum absorption peaks from 3.50 to 3.95 . The calcium displayed hyperchromic and hypsochromic effects on TPH absorption which indicated an interaction. The absorption of the peptide bond is due to the transition of carbonyl electrons from a ground state to excited states $\left(\mathrm{n} \rightarrow \pi^{*}\right)$. Different transitions occur when the spatial structure of peptide chromospheres $(\mathrm{C}=\mathrm{O}$ and $-\mathrm{COOH})$ or auxochromes $(-\mathrm{OH}$ and $-\mathrm{NH} 2)$ is disturbed by binding [21]. Changes in absorption spectra often indicate that the oxygen atom of the carbonyl group and nitrogen of the amino group in the peptide bond are involved in interaction 
[22]. This supported that the blue shift of TPH absorption caused by calcium indicated the interaction between TPH and calcium.

Tryptophan fluorescence of TPH was also affected by calcium (Figure 2C). At the emission maximum of $351 \mathrm{~nm}$, the calcium showed biphasic effects on fluorescence intensity. At low calcium concentrations (0-5 mM), fluorescence emission was increased in quantum yield when the calcium concentration increased. At high calcium concentrations (5-10 mM), however, increasing calcium concentration was accompanied by a decrease in fluorescence intensity. Of note, the calcium concentration at the biphasic turning point coincided with that at the spectral shift point of TPH absorption (Figure 2B). Calcium binding has been shown to cause fluorescence quenching of peptides [23]. Bound calcium might cause the peptide to fold as a more compact structure contributing to the change in fluorescence intensity. [24]

The addition of calcium to TPH caused the peptide-characteristic changes in its absorption spectra and intrinsic tryptophan fluorescence. This suggested that it was the peptides in the hydrolysate that contributed to the calcium-binding activity. Calcium binding by intact proteins is well studied. The most representative examples are EF-hand proteins in which calcium-binding is mediated primarily by the carboxyl side chains and main chain carbonyl oxygens [25]. However, the exact modes of peptide binding to calcium have not yet been elucidated. Previous studies showed that the negatively charged peptides showed greater binding to calcium than the positively charged peptides [6]. The length and amino acid composition of peptides could also influence calcium-binding activities [26].
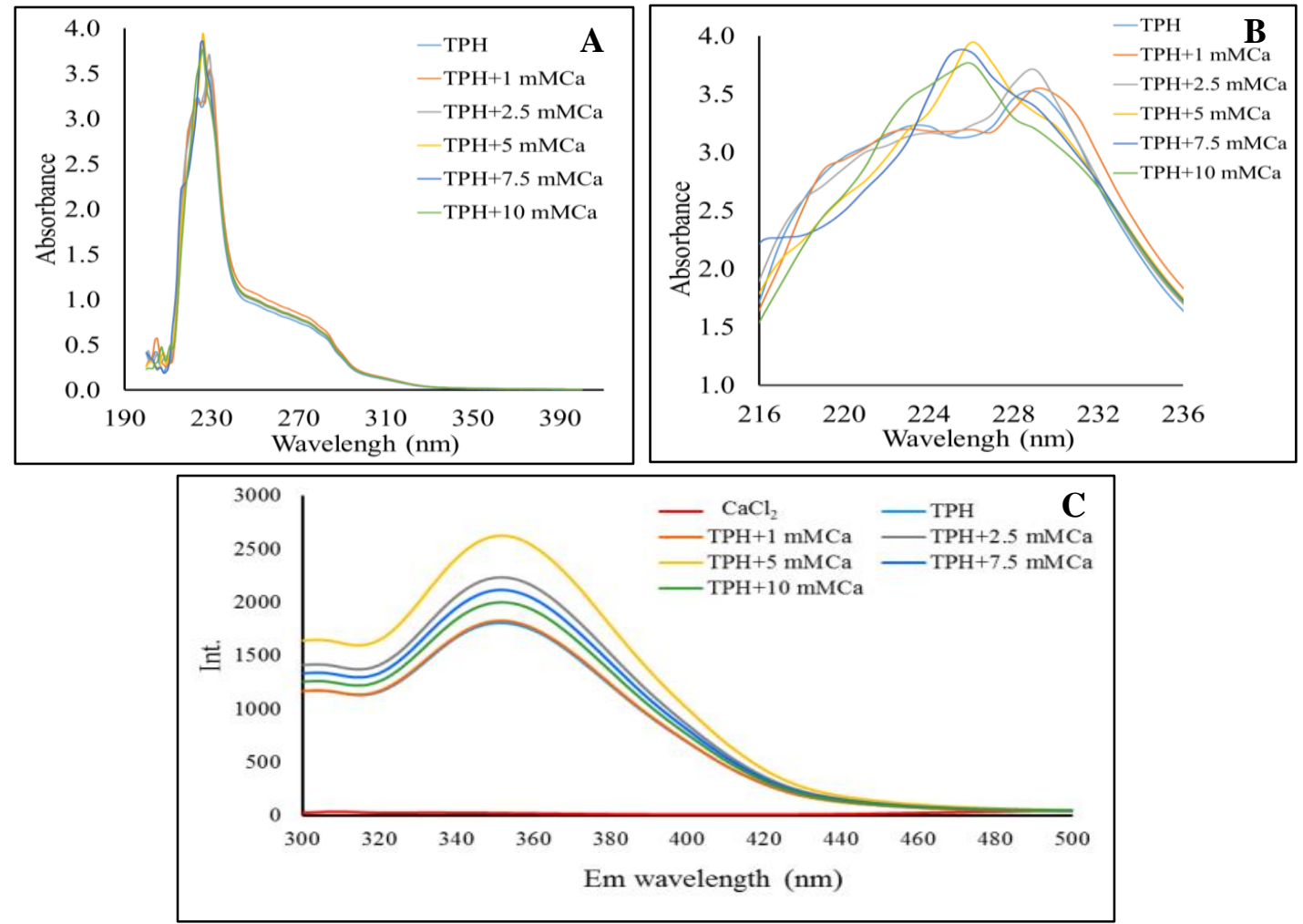

Figure 2. Spectroscopic analysis of TPH-calcium-binding. (A) UV spectra were recorded in the wavelength range of 190-400 $\mathrm{nm}$ in the presence of TPH and various calcium concentrations. (B) Enlarged view of the UV wavelength range $216-236 \mathrm{~nm}$. (C) Fluorescence spectra of TPH were recorded with the excitation wavelength $280 \mathrm{~nm}$ and emission wavelength range $300-450 \mathrm{~nm}$ in the presence of various calcium concentrations. 


\section{Effect of food components on TPH-calcium binding}

Foods are complex mixtures containing a large number of components. Some food components could potentially affect the calcium-binding activity of TPH. We assayed the amount of calcium sequestered in the presence of both TPH and food components including saccharides, amino acids, fatty acids, vitamins, minerals, and chelating agents (Figures 3-6). We found that neither monosaccharides (glucose, fructose, and galactose) nor disaccharides (lactose and sucrose) affected the level of bound calcium (Figure 3).
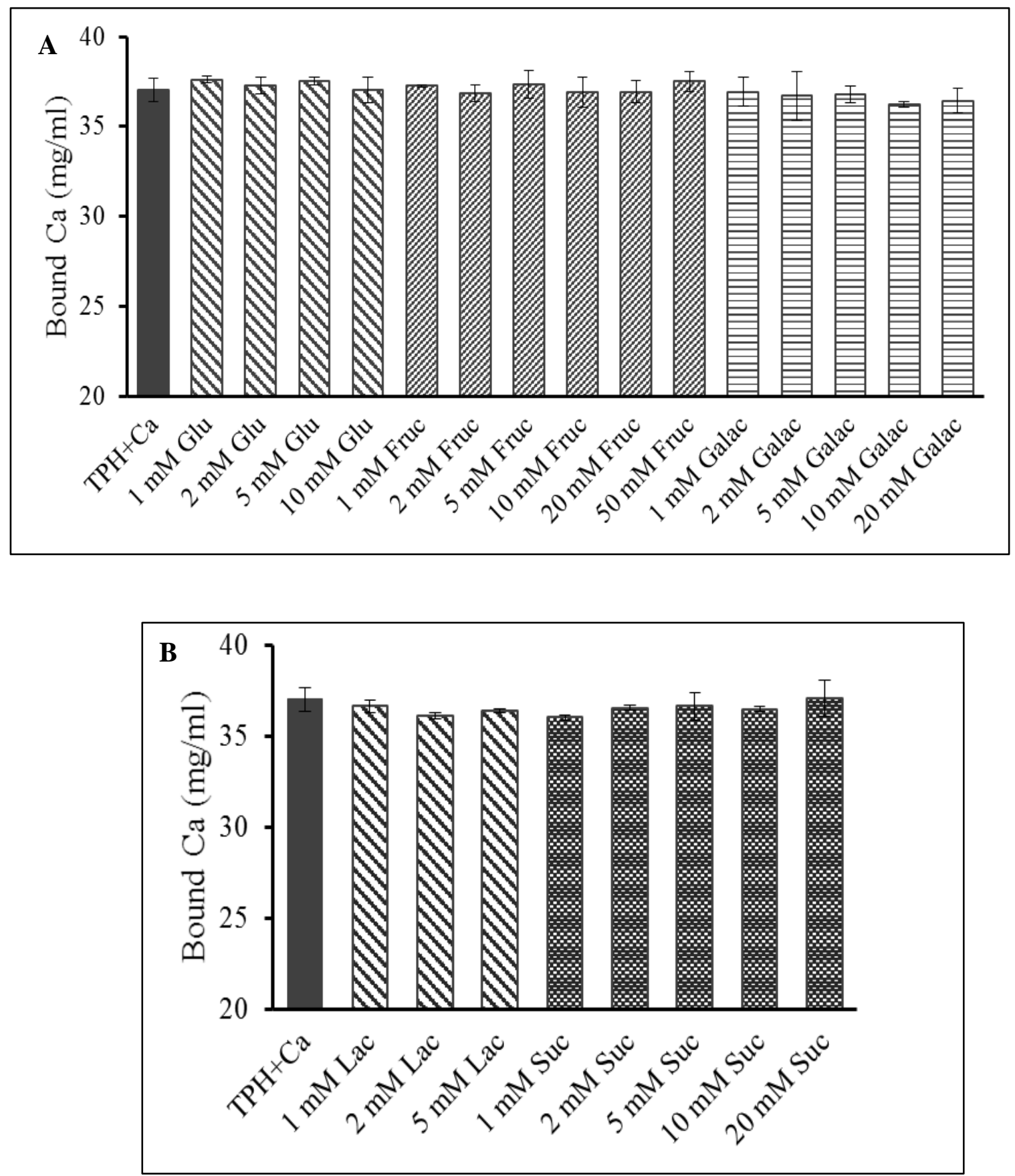

Figure 3. Effects of saccharides on TPH-calcium-binding. (A) Monosaccharides: glucose, fructose, and galactose. (B) Disaccharides: lactose and sucrose. Mean values with the same letters were not significantly different $(\mathrm{p}>0.05)$. 
For amino acids, calcium-binding was not affected by leucine, valine, or threonine (Figures 4A-C) but was significantly increased in the presence of aromatic residues (phenylalanine and tryptophan) or charged residues (lysine, histidine, aspatic acid, and glutamic acid) as shown in Figures 4D-I. This indicated the effect of being amino-acid specific. However, the latter amino acids did not affect the calcium level in the absence of TPH, suggesting that their effect was TPH dependent.
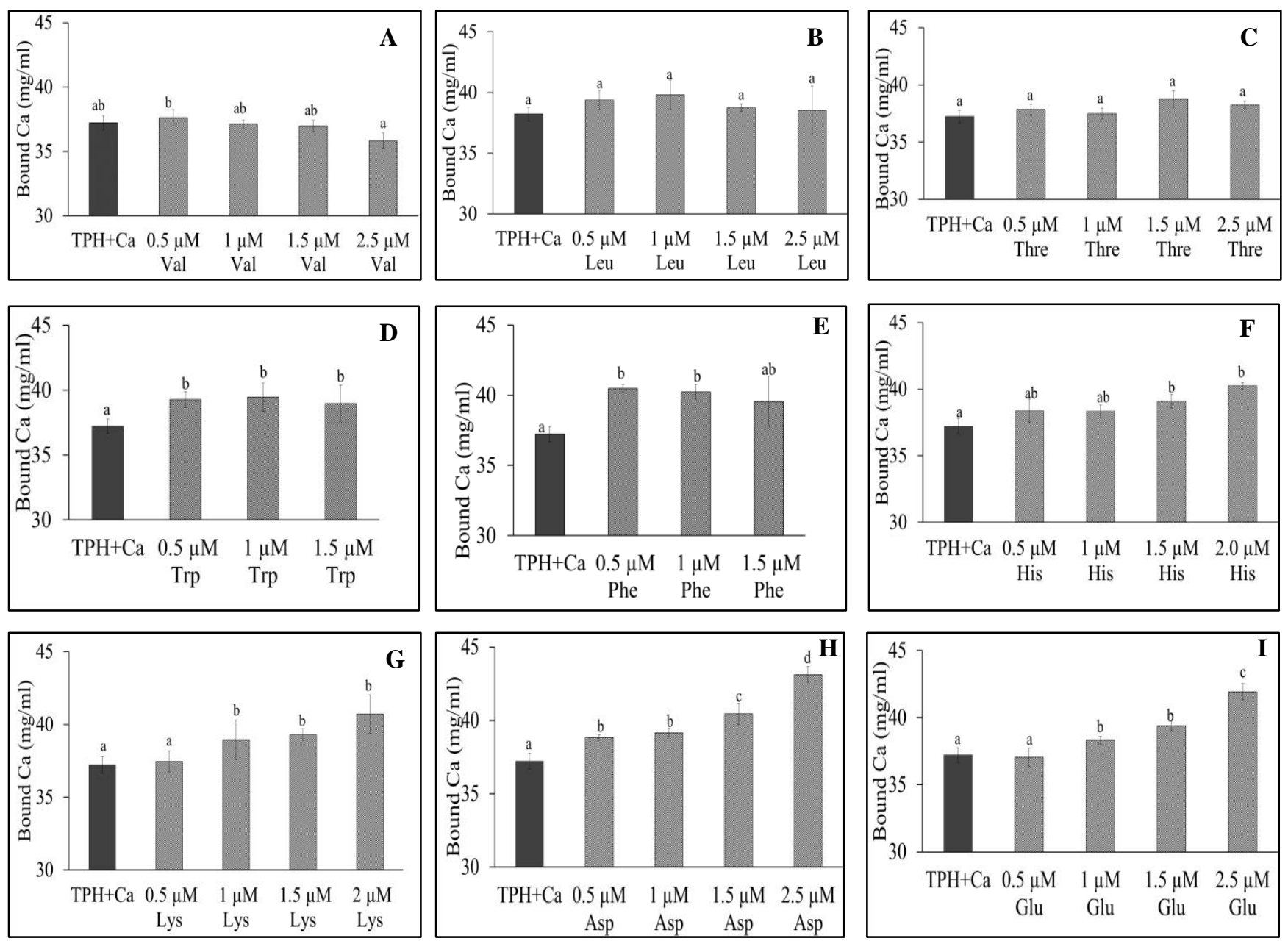

Figure 4. Effects of amino acids on TPH-calcium-binding. (A) Valine. (B) Leucine. (C) Threonine. (D) Tryptophan. (E) Phenylalanine. (F) Histidine. (G) Lysine. (H) Aspartic acid. (I) Glutamic acid. Mean values with different letters were significantly different $(\mathrm{p}<0.05)$.

Fatty acids including linoleic acid and linolenic acid negatively affected calcium-binding (Figure 5A). While vitamin $\mathrm{C}$ slightly increased the amount of bound calcium, vitamin B did not show any significant effect (Figures 5B-C). Vitamin C might directly bind to calcium as its two hydroxyl groups were able to chelate calcium in an aqueous solution [27]. Minerals including magnesium, potassium, and sodium did not make an effect on calcium binding, but the effects of iron were concentration-dependent (Figures 5D-G). The calcium-binding activity significantly increased when adding 1 or $2 \mathrm{mM}$ of $\mathrm{FeCl}_{2}$ but decreased at $10 \mathrm{mM}$ of $\mathrm{FeCl}_{2}$ (Figure 5G).

The most anti-nutritional factors present in green leafy vegetables are oxalate and phytate which bind calcium making it insoluble and decreasing calcium bioavailability [28]. We found that TPH prevented calcium from being precipitated by these chelating agents (Figure 6). Without $\mathrm{TPH}$, free calcium was reduced by more than $50 \%$ by $1 \mathrm{mM}$ of oxalic acid, whereas no 
considerable difference was caused in the presence of TPH (Figure 6A). Similar results were found for phytic acid in which TPH protected calcium from precipitation (Figure 6B). This result suggested that TPH might inhibit calcium chelating by oxalic acid and phytic acid.
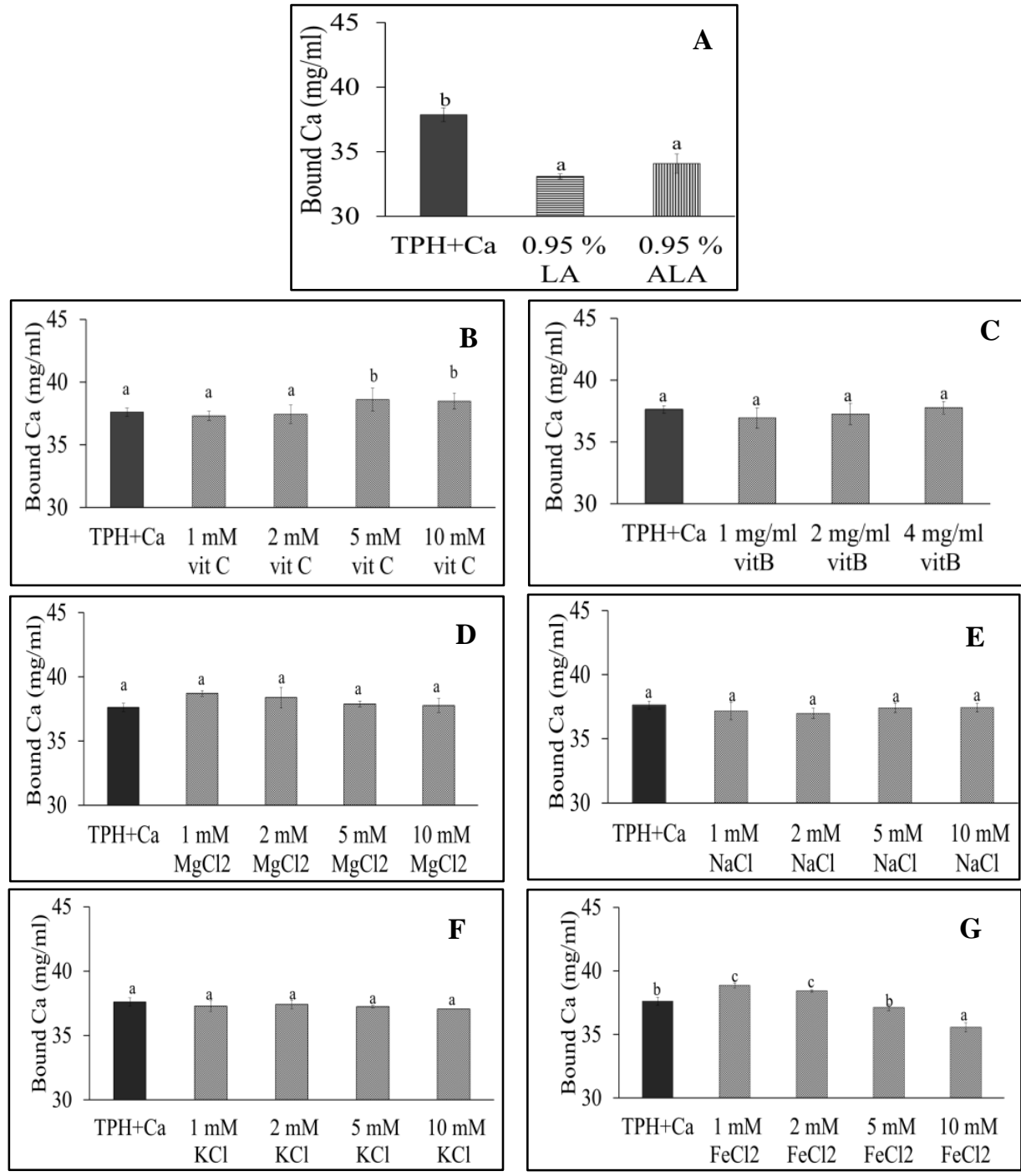

Figure 5. Effects of essential fatty acids, vitamins and macro minerals on TPH-calcium-binding. (A) Linoleic acid and linolenic acid. (B) Ascorbic acid (vitamin C). (C) Vitamin B. (D) $\mathrm{MgCl}_{2}$. (E) $\mathrm{NaCl}$. (F) $\mathrm{KCl}$. (G) $\mathrm{FeCl}_{2}$. Mean values with different letters were significantly different $(\mathrm{p}<0.05)$.
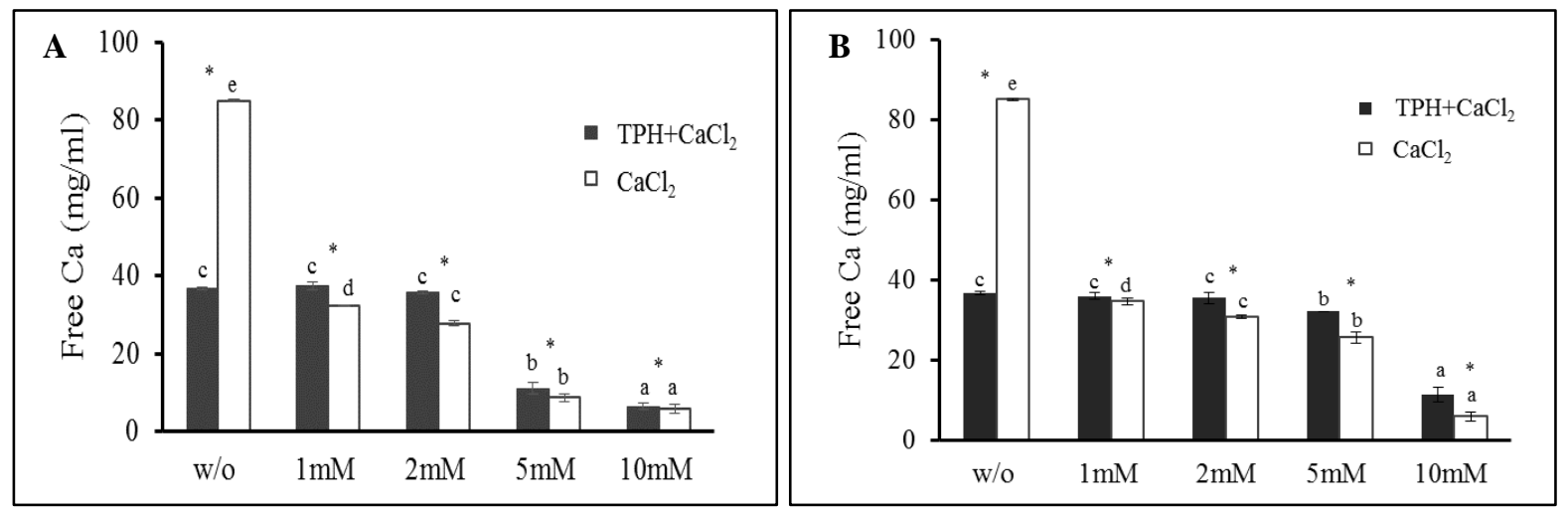

Figure 6. TPH reduced calcium precipitation by chelating agents. (A) Oxalic acid. (B) Phytic acid. Mean values with different letters were significantly different $(p<0.05)$. 


\section{TPH-calcium binding activity maintained in the simulated human digestion system}

Food protein digestion occurs mostly in the stomach and duodenum. The primary digestive enzymes are pepsin secreted by the stomach and pancreatin - a collection of enzymes secreted by the pancreas. To evaluate the effect of these digestive enzymes on TPH-calcium-binding, TPH was subjected to in vitro pepsin-pancreatin digestion in a simulated human digestion system (Figure 7). The calcium-binding activities of TPH were not considerably different before and after simulated gastrointestinal digestion. This activity was reduced only by $5 \%$ at $3 \mathrm{~h}$ in pepsin digestion, whereas it was slightly increased at $2 \mathrm{~h}$ in pancreatin digestion (Figure 7A). This indicated that the calcium-binding activity of TPH was stable in this in vitro digestion model. Other bio-functional peptides or hydrolysates also showed similar gastrointestinal stability. The horse mackerel protein hydrolysate was stable for $5 \mathrm{~h}$ in a simulated two-stage gastrointestinal digestion [29].
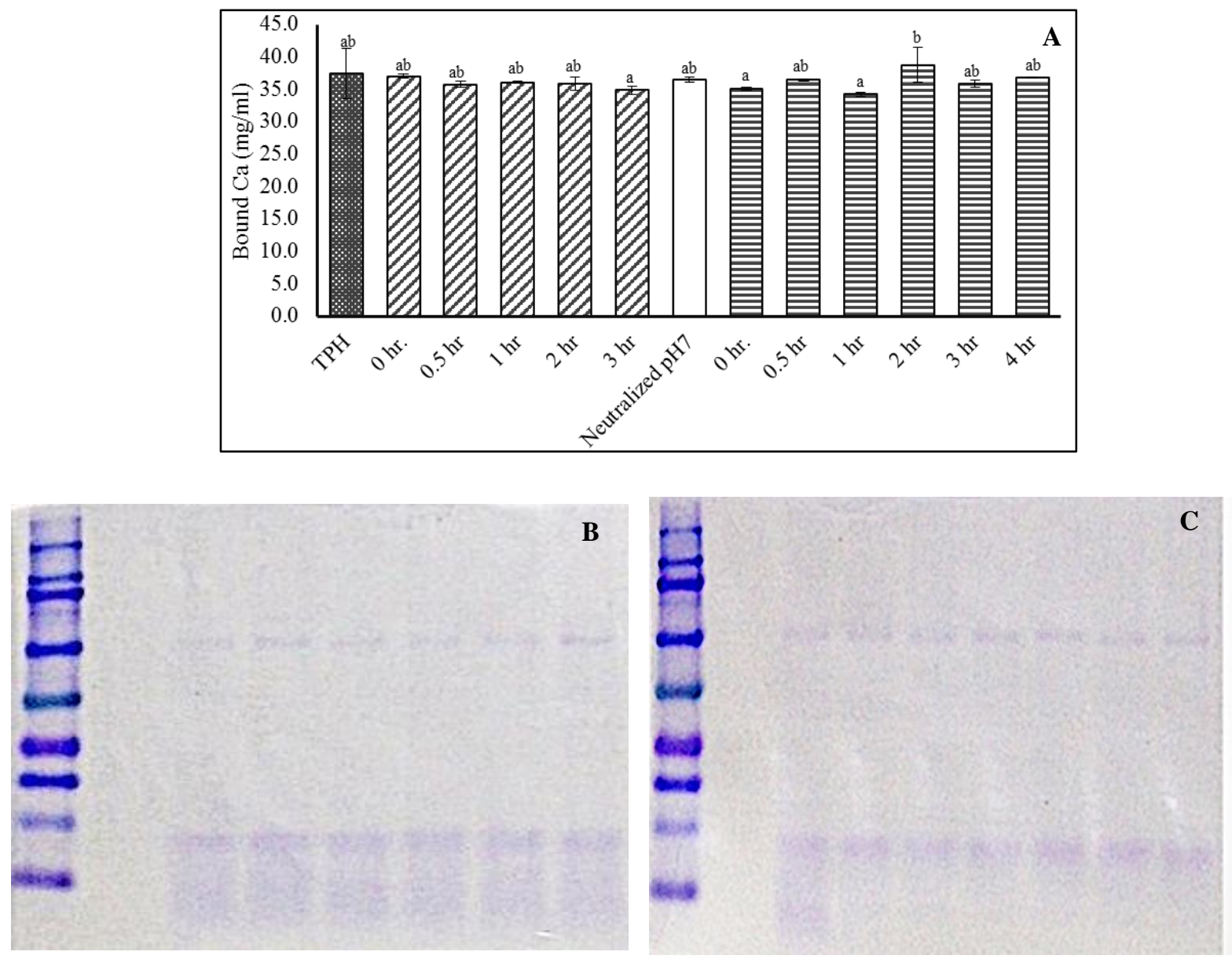

Figure 7. The stability of TPH-calcium-binding in the simulated gastrointestinal digestion system. (A) Time course of TPH-calcium-binding activities during sequential pepsin-pancreatin digestion. Mean values with different letters were significantly different $(\mathrm{p}<0.05)$. Tricine SDS-PAGE analysis of the peptide patterns of TPH after digestion by (B) pepsin and (C) pancreatin.

The peptide distribution pattern of the hydrolysate was not affected by this digestion. The calcium-binding capacity of the hydrolysate did not change significantly either during the digestion. Another study showed that the in vitro pepsin-pancreatin digestion of milk and kefir resulted in a slight increase in their calcium-binding capacities [30]. This digestion made milk proteins relatively resistant to proteolytic degradation by kefir culture during fermentation. 
The peptide patterns of TPH, however, were slightly different before and after simulated gastrointestinal digestion (Figures 7B-C). Before digestion, there were three major groups of peptides in the hydrolysate: bands at the $10 \mathrm{kDa}, 15 \mathrm{kDa}$, and $50 \mathrm{kDa}$. After digestion, the amount of the peptides at $10 \mathrm{kDa}$ band was significantly reduced. This suggested that these peptides were not responsible for calcium binding as the calcium-binding activities of TPH remains the same before and after digestion (Figure 7A).

To explore the potential of TPH as a functional food for promoting calcium absorption, the calcium binding of TPH was assessed for gastrointestinal stability and compatibility with food matrices. The calcium-binding activity of TPH will probably be maintained in vivo after its consumption because the binding was stable in the simulated gastrointestinal digestion system. Pepsin and pancreatin did not considerably change the calcium-binding activity although there were some changes in the peptide patterns of the hydrolysate. The calcium binding of TPH was also compatible with food matrices. Most food components tested including all saccharides, amino acids and vitamins showed positive or no effects on calcium-binding. This suggested that the calcium-binding activity of TPH will likely be preserved in the complex multi-component food matrices. However, some food components including fatty acids and a high concentration of iron reduced calcium-binding. This implicated that the calcium binding activity of TPH could be maximized if the food contains low levels of fatty acids and iron.

\section{TPH enhances transepithelial calcium transport}

Peptide binding to calcium has the potential to improve calcium uptake. One possible mechanism is the binding enhancing calcium across the intestinal epithelium. To test if TPH had such an effect, calcium transport was studied using an intestinal permeability cell model in which Caco-2 cells were cultured as monolayer used to predict calcium absorption across tight junctions. Caco-2 cells are human epithelial colorectal adenocarcinoma cells that are commonly used for studying the intestinal permeability of drugs and minerals [31, 32, 33]. Differentiated Caco-2 cells form tight junctions functionally similar to enterocytes lining the small intestine. The result found that TPH was not toxic to Caco-2 cells at a concentration of up to $1 \mathrm{mg} / \mathrm{ml}$, the percentage of cell viability still above $80 \%$ at this concentration (Figure 8A). Because of its minimal effect on cell viability, the concentrations of TPH used in subsequent calcium transport experiments all referred to this concentration.

In the absence of TPH, calcium transport was time and concentration-dependent (Figure 8B). The transport of calcium was linear between 30 and $150 \mathrm{~min}$ at calcium concentrations of 2.5 and $5.0 \mathrm{mM}$ but became non-linear at higher calcium concentrations (7.5 and $10.0 \mathrm{mM}$ ) (Figure 8B). The concentration dependence of calcium transport was non-linear for all time points tested (Figure 8B), which suggested the presence of a saturable transport component. In the presence of $\mathrm{TPH}$, calcium transport was changed in its time dependence behavior in which the calcium transport became non-linear between 30 and 150 min (Figure 8C). However, TPH significantly enhanced calcium transport across the Caco-2 cell monolayer (Figure 8D). The permeability coefficient (Papp) of calcium transport in the presence of TPH was significantly higher than that in the absence of TPH. The highest permeability coefficient was observed with $1.0 \mathrm{mg} / \mathrm{ml}$ of TPH in which there was more than a two-fold increase in calcium transport. However, further increasing TPH concentration (to $2 \mathrm{mg} / \mathrm{ml}$ ) reduced calcium transport. This result was concordance with the previous report form CPPs [34], one possible reason was reduced cell viability when TPH 
concentration was higher than $1 \mathrm{mg} / \mathrm{ml}$ (Figure 8A). Nevertheless, our result demonstrated that TPH promoted calcium absorption in vitro cell permeability model.

TPH has the potential to enhance calcium bioavailability. This hypothesis was based on two findings from this study. We found that calcium precipitation by oxalate and phytate was significantly reduced in the presence of TPH. Oxalate is known to interfere with calcium absorption by forming insoluble salts of calcium. Phytate is a hexaphosphate of inositol and greatly inhibits calcium uptake [35]. This suggested that TPH could potentially enhance calcium absorption in high-oxalate or high-phytate foods.
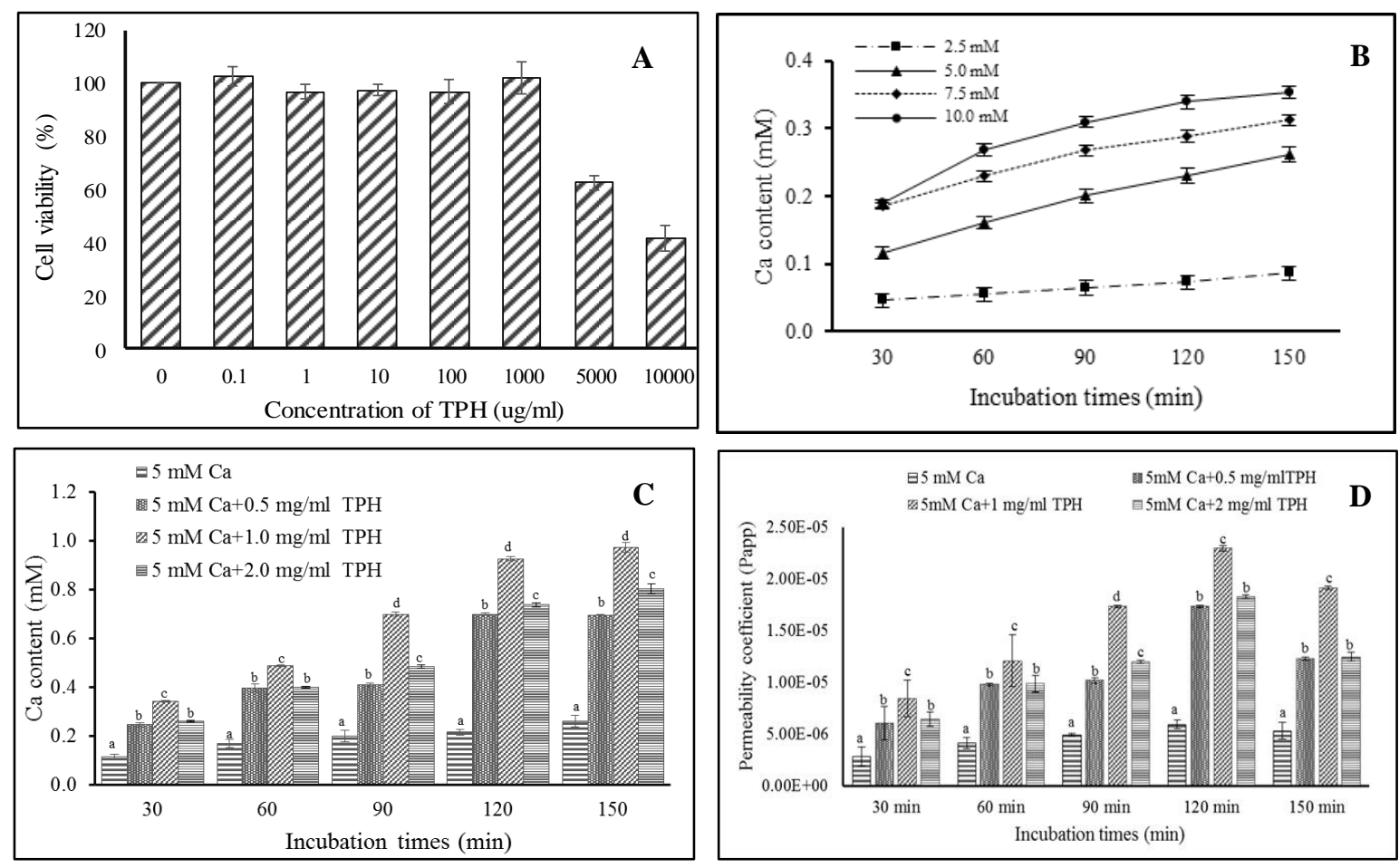

Figure 8. TPH enhanced calcium transport across the Caco- 2 cell monolayer. (A) Effects of TPH on Caco-2 cell viability. Calcium transport in the absence of TPH (B). Calcium transport in the presence of TPH (C) and as a function of time. TPH increased the permeability coefficients of calcium transport (D). Mean values with different letters were significantly different $(\mathrm{p}<0.05)$.

The second finding that supported the health-promoting potential of TPH was TPH enhancing transepithelial calcium transport in the Caco- 2 cell permeability model. Caco- 2 cells are widely used as an in vitro model of the human small intestinal mucosa [36]. Because of differentiated Caco-2 cells morphologically and functionally resembling the intestinal barrier, they have been extensively used for intestinal transport studies [17]. This cell model mimics processes including transcellular transport, paracellular transport, and some aspects of efflux and active transport [37]. While the exact mechanisms of TPH promoting calcium transport need further investigation, both paracellular and transcellular transports could be affected by the calcium-binding peptides in TPH. Peptides can serve as a carrier for paracellular transport of chemicals across the tight junction [38]. They can also directly target proteins of the apical junctional complex causing the opening of the tight junction [39]. However, recent studies showed that casein phosphopeptides (CPPs) were likely to influence the transcellular pathway of intestinal calcium absorption rather than the paracellular pathway [40]. Enhanced calcium transport in Caco-2 cells was due to CPPs affecting 
the transcellular pathway by upregulating the expression of TRPV6. Nevertheless, the ability of TPH to bind calcium, promote transepithelial calcium transport and prevent calcium precipitation by the chelating agents warranted future investigation of its effects on calcium bioavailability and homeostasis.

\section{CONCLUSION}

Tilapia protein hydrolysate (TPH) produced by alcalase hydrolysis of Nile tilapia was shown calcium-binding activity. However, such an activity should probably be maintained in vivo after its consumption because the binding was stable in the simulated gastrointestinal digestion system. The binding was also compatible with food matrices. Most food components tested including all saccharides, amino acids, and vitamins showed positive or no effects on calcium binding. However, some food components including fatty acids and a high concentration of iron reduced calcium binding. This implicated that the calcium-binding activity of TPH could be maximized if the food contains low levels of fatty acids and iron. Also, TPH has the potential to enhance calcium bioavailability. Calcium precipitation by oxalate and phytate was significantly reduced in the presence of TPH and that TPH enhanced transepithelial calcium transport in the Caco- 2 cell permeability model. These together support a health-promoting potential of TPH.

List of Abbreviations: CPPs, casein phosphopeptides; TPH, tilapia protein hydrolysate; ATCC, The American Type Cell Collection; TEER, transepithelial electrical resistance.

Completing Interests: There are no conflicts of interest to declare.

Authors' Contributions: Nualpun Sirinupong, Nongphon Towaltana, and Zhe Yang, designed the research; Nootjaree Buaduang and Worrapanit Chansuwan performed the research and draft manuscript; Worrapanit Chansuwan, Nualpun Sirinupong and Nongphon Towaltana analyzed the data. Nualpun Sirinupong, and Zhe Yang edited the manuscript and had primary responsibility for the final content. All authors read and approved the final version of the manuscript.

Acknowledgements and Funding: This work was supported by government budget from Prince of Songkla University (AGR580340S).

\section{REFERENCES}

1. Cilla A, Lagarda MJ, Alegría A, De Ancos B, Cano MP, Sánchez-Moreno C, Plaza L, et al.: Effect of processing and food matrix on calcium and phosphorous bioavailability from milk-based fruit beverages in Caco-2 cells. Food Research International 2001, 44(9): 3030-3038.

2. Bronner F: Mechanisms of intestinal calcium absorption. Journal of cellular biochemistry 2003, 88(2): 387-393.

3. Charoenphandhu N, Krishnamra N: Prolactin is an important regulator of intestinal calcium transport. Canadian Journal of Physiology and Pharmacology 2007, 85(6): 569581. 
4. Yong Guo J, Wen Wen F, Mei Hu M: Preparation and structure characterization of soluble bone collagen peptide chelating calcium. African Journal of Biotechnology 2011, 10(50):10204-10211.

5. Gravaghi C, Del Favero E, Cantu L, Donetti E, Bedoni M, Fiorilli A, Tettamanti G, et al.: Casein phosphopeptide promotion of calcium uptake in HT-29 cells-relationship between biological activity and supramolecular structure. FEBS Journal 2007, 274(19):4999-5011.

6. Lu Y, Nie R, Li F, Liu Z: Effects of Calcium-Binding Peptide from Tilapia Scale Protein Hydrolysates on Calcium Absorption in Caco-2 Cells. Journal of Aquatic Food Product Technology 2016, 25:1213-1220.

7. Erdmann K, Cheung BWY, Schröder H: The possible roles of food-derived bioactive peptides in reducing the risk of cardiovascular disease. The Journal of Nutritional Biochemistry 2008, 19(10):643-654.

8. Cao Y, Miao J, Liu G, Luo Z, Xia Z, Liu F, Yao M, et al.: Bioactive Peptides Isolated from Casein Phosphopeptides Enhance Calcium and Magnesium Uptake in Caco-2 Cell Monolayers. Journal of Agricultural and Food Chemistry 2007, 65(11):2307-2314.

9. Perego S, Del favero E, De Luca P, Dal Piaz F, Fiorilli A, Cantu' L, Ferraretto A: Calcium bioaccessibility and uptake by human intestinal like cells following in vitro digestion of casein phosphopeptide-calcium aggregates. Food \& Function 2015, 6(6):1796-1807.

10. Daengprok W, Garnjanagoonchorn W, Naivikul O, Pornsinlpatip P, Issigonis K, Mine Y: Chicken Eggshell Matrix Proteins Enhance Calcium Transport in the Human Intestinal Epithelial Cells, Caco-2. Journal of Agricultural and Food Chemistry 2003, 51(20):6056-6061.

11. Charoenphun N, Cheirsilp B, Sirinupong N, Youravong W: Calcium-binding peptides derived from tilapia (Oreochromis niloticus) protein hydrolysate. European Food Research and Technology 2012, 236(1):57-63.

12. Sun N, Wu H, Du M, Tang Y, Liu H, Fu Y, Zhu B: Food protein-derived calcium chelating peptides: A review. Trends in Food Science \& Technology 2016, 58:140-148.

13. Clement S, Lovell RT: Comparison of processing yield and nutrient composition of cultured Nile tilapia (Oreochromis niloticus) and channel catfish (Ictalurus punctatus). Aquaculture 1994, 119(2-3):299-310.

14. Tejpal CS, Vijayagopal P, Elavarasan K, Linga prabu D, Lekshmi RGK, Asha KK, Anandan R, et al.: Antioxidant, functional properties and amino acid composition of pepsin-derived protein hydrolysates from whole tilapia waste as influenced by preprocessing ice storage. Journal of Food Science and Technology 2017, 54(13):42574267.

15. Cinq-Mars CD, Hu C, Kitts DD, Li-Chan ECY: Investigations into Inhibitor Type and Mode, Simulated Gastrointestinal Digestion, and Cell Transport of the Angiotensin IConverting Enzyme-Inhibitory Peptides in Pacific Hake (Merluccius productus) Fillet Hydrolysate. Journal of Agricultural and Food Chemistry 2008, 56:410-419.

16. Lo WMY, Li-Chan, ECY: Angiotensin I converting enzyme inhibitory peptides from in vitro pepsin-pancreatin digestion of soy protein. Journal of Agricultural and Food Chemistry 2005, 53(9):3369-3376. 
17. Hansen MB, Nielsen SE, Berg K: Re-examination and further development of a precise and rapid dye method for measuring cell growth/cell kill. Journal of Immunological Methods 1989, 119(2):203-210.

18. Twentyman PR, Luscombe M: A study of some variables in a tetrazolium dye (MTT) based assay for cell growth and chemosensitivity 1987, British Journal of Cancer 56(3):279-285.

19. Srinivasan B, Kolli AR, Esch MB, Abaci HE, Shuler ML, Hickman JJ: TEER Measurement Techniques for In Vitro Barrier Model Systems. Journal of Laboratory Automation 2015, 20(2):107-126.

20. Faassen F, Kelder J, Lenders J, Onderwater R, Vromans H: Physicochemical Properties and Transport of Steroids Across Caco-2 Cells. 2003, Pharmaceutical Research 20(2):177-186.

21. Armas A, Sonois V, Mothes E, Mazarguil H, Faller P: Zinc( II) binds to the neuroprotective peptide humanin. Journal of Inorganic Biochemistry 2006, 100: 16721678.

22. Blindauer CA, Harvey I, Bunyan KE, Stewart AJ, Sleep D, Harrison DJ, Berezenko S, et al.: Structure, Properties, and Engineering of the Major Zinc Binding Site on Human Albumin. Journal of Biological Chemistry 2009, 284(34):23116-23124.

23. Uppal R, Lakshmi KV, Valentine AM: Isolation and characterization of the iron-binding properties of a primitive monolobal transferrin from Ciona intestinalis. JBIC Journal of Biological Inorganic Chemistry 2008, 13:873-885.

24. Cai X, Lin J, Wang S: Novel Peptide with Specific Calcium-Binding Capacity from Schizochytrium sp. Protein Hydrolysates and Calcium Bioavailability in Caco-2 Cells. Marine Drugs 2016, 15(1):3.

25. Lewit-Bentley A, Rety S: EF-hand calcium-binding proteins. Current opinion in structural biology 2000, 10(6):637-643.

26. Chaud MV, Izumi C, Nahaal Z, Shuhama T, Bianchi MDLP, Freitas OD: Iron Derivatives from Casein Hydrolysates as a Potential Source in the Treatment of Iron Deficiency. Journal of Agricultural and Food Chemistry 2002, 50(4): 871-877.

27. Tajmir-Riahi HA: Coordination chemistry of vitamin C. Part I. Interaction of Lascorbic acid with alkaline earth metal ions in the crystalline solid and aqueous solution. Journal of Inorganic Biochemistry 1990, 40: 181-188.

28. Amalraj A, Pius A: Bioavailability of calcium and its absorption inhibitors in raw and cooked green leafy vegetables commonly consumed in India - An in vitro study. Food Chemistry 2015, 170:430-436.

29. Huang GR, Zhang WT, Sun JY: Stability of Mackerel ( Trachurus japonicas) Hydrolysate with Iron-Binding Capacity in Simulated Gastrointestinal Fluids. American Journal of Food Technology 2015, 10:158-166.

30. Nehir ES, Karakaya S, Simsek S, Dupont D, Menfaatli E, Eker AT: In vitro digestibility of goat milk and kefir with a new standardised static digestion method (INFOGEST cost action) and bioactivities of the resultant peptides. Food \& Function 2015, 6(7):23222330. 
31. Camara F, Barbera R, Amaro MA, Farre R: Calcium, iron, zinc and copper transport and uptake by Caco-2 cells in school meals: Influence of protein and mineral interactions. Food Chemistry 2007, 100(3):1085-1092.

32. Hou T, Wang C, Ma Z, Shi W, Weiwei L, He H: Desalted Duck Egg White Peptides: Promotion of Calcium Uptake and Structure Characterization. Journal of Agricultural and Food Chemistry 2015, 63(37):8170-8176.

33. Lu Y, Nie R, LI F, Liu Z: Effects of Calcium-Binding Peptide from Tilapia Scale Protein Hydrolysates on Calcium Absorption in Caco-2 Cells. Journal of Aquatic Food Product Technology 2016, 25(8):1213-1220.

34. Gravaghi C, Del Favero E, Cantu L, Donetti E, Bedoni M, Fiorilli A, Tettamanti G, et al.: Casein phosphopeptide promotion of calcium uptake in HT-29 cells relationship between biological activity and supramolecular structure. FEBS Journal 2007, 274:4999-5011.

35. Gupta S, Lakshmi AJ, Prakash J: In vitro bioavailability of calcium and iron from selected green leafy vegetables. Journal of the Science of Food and Agriculture 2006, 86(13):2147-2152.

36. Le Ferrec E, Chesne C, Artusson P, Brayden D, Fabre G, Gires P, Guillou F, et al.: In vitro models of the intestinal barrier. The report and recommendations of ECVAM Workshop 46. European Centre for the Validation of Alternative methods. Alternatives to laboratory animals: ATLA 2001, 29(6):649-668.

37. Giuliano AR, Wood RJ: Vitamin D-regulated calcium transport in Caco-2 cells: unique in vitro model. The American journal of physiology 1991, 260(2 Pt 1):G207-212.

38. Laksitorini M, Prasasty VD, Kiptoo PK, Siahaan TJ: Pathways and progress in improving drug delivery through the intestinal mucosa and blood-brain barriers. Therapeutic delivery 2014, 5(10):1143-1163.

39. Gonzalez-Mariscal L, Posadas Y, Miranda J, Uc PY, Ortega-Olvera JM, Hernandez S: Strategies that Target Tight Junctions for Enhanced Drug Delivery. Current pharmaceutical design 2016, 22(35):5313-5346.

40. Liu G, Sun S, Guo B, Miao B, Luo Z, Xia Z, Ying D, et al.: Bioactive peptide isolated from casein phosphopeptides promotes calcium uptake in vitro and in vivo. Food Function 2018, 9(4):2251-2260. 